\title{
Copulatory behaviour increases sperm viability in female spiders
}

\author{
FRANCO CARGNELUTTI ${ }^{1,2, *}$, LUCIA CALBACHO-ROSA $^{1,2}$, DIEGO UÑATES $^{1,2}$, \\ LUIZ ERNESTO COSTA-SCHMIDT ${ }^{3,4, \bullet}$, ALEX CÓRDOBA-AGUILAR $^{5}$ and \\ ALFREDO VICENTE PERETTI ${ }^{1,2}$
}
${ }^{1}$ Facultad de Ciencias Exactas, Físicas y Naturales, Departamento de Diversidad Biológica y Ecología, Universidad Nacional de Córdoba, Córdoba, Argentina
${ }^{2}$ Consejo Nacional de Investigaciones Científicas y Técnicas (CONICET), Laboratorio de Biología
Reproductiva y Evolución, Instituto de Diversidad y Ecología Animal (IDEA), Córdoba, Argentina
${ }^{3}$ Programa de Pós-Graduação em Biologia, Universidade do Vale do Rio dos Sinos, Rio Grande do Sul, Brasil
${ }^{4}$ Departamento de Ecologia, Zoologia e Genética, Universidade Federal de Pelotas, Rio Grande do Sul, Brasil
${ }^{5}$ Departamento de Ecología Evolutiva, Instituto de Ecología, Universidad Nacional Autónoma de México, Apdo. Postal 70-275, Ciudad Universitaria, 04510 Mexico City, Mexico

Received 28 May 2020; revised 17 July 2020; accepted for publication 28 July 2020

\begin{abstract}
One remarkable reproductive feature in animals with internal fertilization is a reduction in sperm viability over time in females. Whether this reduction is driven by male-male competition and/or cryptic female choice is unclear. From the perspective of cryptic female choice, we postulated that sperm viability is affected by a particular male copulatory behaviour. In this study, we investigated the following aspects: (1) sperm viability in mated females vs. males; (2) whether sperm viability varies temporally after mating; and (3) whether male copulatory behaviour covaries positively with sperm viability within females. We used the spider Holocnemus pluchei, whose males use several copulatory behaviours to court females. We found that females that stored sperm for 4 or 15 days showed no difference in sperm viability but had lower sperm viability compared with males, and males that performed a longer post-insemination behaviour had higher sperm viability inside the female. It is unclear how sperm viability is reduced and how male post-insemination behaviour affects this. It is possible that extending copulation allows males to induce females to keep sperm alive for longer. This result is predicted by theory whereby males induce females to facilitate sperm to reach and fertilize eggs based on male postcopulatory behaviour.
\end{abstract}

ADDITIONAL KEYWORDS: copulatory behaviour - Holocnemus pluchei - sperm viability.

\section{INTRODUCTION}

Sperm storage in the female reproductive tract is widespread in vertebrates and invertebrates, but it is species specific. This storage can last from a few hours to years (Orr \& Zuk, 2012). Once inside the female, the sperm face new challenges, given that the female tract can be highly selective (reviewed by Fitzpatrick \& Lüpold, 2014; Kekäläinen \& Evans, 2018). Evidence of this process is the decrease in sperm viability (the

*Corresponding author. E-mail: francocarg@gmail.com proportion of living sperm cells divided by the total number of sperm cells inside an ejaculate) that takes place during storage in females in several species. For example, Snook \& Hosken (2004) found a 70\% decrease in Drosophila melanogaster Meigen, 1830 (however, see also Stewart et al., 2007; Radhakrishnan \& Fedorka, 2011). Although this fly example can be dramatic, other species also show marked decreases in sperm viability [i.e. Scathophaga stercoria (Linnaeus, 1758), Diptera (Bernasconi et al., 2002); Photinus greeni Lloyd, 1969 and Photinus ignites Fall, 1927, Coleoptera (Demary, 2005); Bombus terrestris Linnaeus, 1758, Hymenoptera (Greeff \& Schmid-Hempel, 2008); Mnais 
pruinosa Selys, 1853 and Calopteryx cornelia Selys, 1853, Odonata (Tsuchiya \& Hayashi, 2010)]. Moreover, the exact mechanisms of sperm viability decline have not been fully clarified, although it might be related to an intrinsic property of males (i.e. ejaculate quality characteristics that make sperm vary viability; Rodriguez de Souza et al., 2020) that could act in concert with the selective forces that take place in the female genital tract (Hosken et al., 2001; Bernasconi et al., 2002; Snook \& Hosken, 2004; Holman \& Snook, 2008). Other explanations point to a trade-off between the immune system of the female, which has proved costly to maintain, for example in invertebrates (Rolff \& Siva-Jothy, 2003), and the ability to keep stored sperm alive (Baer et al., 2006). It has also been suggested that the decrease in sperm viability is due to the ageing of sperm in female storage structures (reviewed by Reinhardt, 2007). It is also possible that a reduction in sperm viability could be attributable to a process associated with the immune function of individuals, mainly during mating (Birkhead et al., 1993; Pitnick et al., 2009; Wigby et al., 2019).

There are several known mechanisms by which females keep sperm alive; for example, by glandular secretions (den Boer et al., 2008, 2009; Baer et al., 2009; Gasparini \& Evans, 2013), decreasing reactive oxygen species (Heifetz \& Rivlin, 2010; Ribou \& Reinhardt, 2012; Reinhardt \& Ribou, 2013) or decreasing the immune response within storage sites (Dávila et al., 2015). Linked to this female role, male copulatory courtship might trigger female responses affecting sperm-related functions, such as sperm transfer, sperm storage or biased use of sperm for fertilization from some particular male phenotypes (Bloch Qazi, 2003; for a review of copulatory courtship and its possible effects on females, see Eberhard, 1996, 2015). It is also possible that male behaviours associated with copulatory courtship might induce female responses that affect sperm viability. To our knowledge, this idea has been little explored.

Within arthropods, spiders are a poorly explored model of sperm viability. Only the studies by Archibald et al. (2014) and Cargnelutti et al. (2019) have explored this topic, but have only described sperm viability in males, without examining female roles in this. Spiders have reproductive characteristics that render them an appealing model to study the dynamics and evolutionary forces acting on the sperm stored by females. First, like other arthropods (Simmons, 2001), many spider species have specialized structures, called spermathecae, for the storage of spermatozoa (Foelix, 2011). Second, females store sperm transferred by males in their encapsulated (inactive) state, in many cases only favouring decapsulation at the time of egg fertilization (Eberhard, 2004; Herberstein et al., 2011; Vöcking et al., 2013). The reason for the transfer of encapsulated sperm to females and why this characteristic evolved in the first place remain unclear. However, the female storage might negatively affect the sperm viability, which could explain, for example, why the spermatozoa sheath acts as a protective trait (Alberti, 1990; Michalik \& Lipke, 2013). Following this reasoning, we can interpret the sperm protection system and the selective female environment as a result of sexual conflict (Birkhead et al., 1993). In this case, females and males are not necessarily sharing the same evolutionary interests, and this is why spermatozoa have to be protected.

Females of the pholcid spider Holocnemus pluchei (Scopoli, 1763) store their sperm in their uterus externus (also known as the genital cavity), which is characterized by a pair of dorsal pore plates through which the vulval glands discharge their products (Huber, 1995). This site is separated from the uterus internus by a complex structure called the valve (Huber, 1995). As in other family members (Uhl, 1996), the sperm stored in the uterus externus is very close to the genital opening of the female. Females have control over the opening of their genitalia, which can expose the sperm, for example, to the external air. This spatial location of the spermatozoa exposes them to several environmental stressful factors (e.g. desiccation, pathogen exposure and humidity), unlikely to occur in other spider families. During mating, H. pluchei males that copulate with virgin females perform two copulatory phases (I and II). During phase I, the male performs simultaneous movements with his pedipalps inside the female genital opening. This behaviour includes strong squeezes and torsion movements that twist and squeeze the female abdomen (Huber, 1995; Calbacho-Rosa et al., 2013). Hereafter, we refer to phase II as male post-insemination behaviour (CalbachoRosa et al., 2013). Sperm transfer takes place in the first 3 min of phase I (Cargnelutti, 2020), which is followed by the post-insemination behaviour, which is an immobile phase during which the male keeps his pedipalps inserted in the female genital opening. However, despite the apparent absence of pedipalp movements, males might still move their pedipalps inside the female genital opening, serving a copulatory courtship function (Eberhard, 1996; Cargnelutti et al., 2018). Another possibility is that the pressure exerted by male with the distal region of the procursus (a unique modification on the pedipalp tarsus; Huber, 2014) near the area of the female's valve (see Huber, 1995) can stimulate the female without movement of the pedipalps. Such immobility implies that females allow males to do it. Given this male immobility and the presumed female tolerant behaviour (Calbacho-Rosa $\&$ Peretti, 2015), we suggest a central role for cryptic female choice in this model system. Previous studies have proposed the following behavioural aspects to be 
likely copulatory courtship traits: pedipalp movements (reviewed by Calbacho-Rosa \& Peretti, 2015; Cargnelutti et al., 2018), duration of post-insemination behaviour (only during copulation with virgin females; see Calbacho-Rosa et al., 2013; Cargnelutti et al., 2018) and the body vibrations performed during copulation (Calbacho-Rosa et al., 2013; Calbacho-Rosa \& Peretti, 2015). These vibrations are vigorous shakes carried out mainly by the body of the male that induce the couple to move on the web during copulation. These reproductive features make $H$. pluchei an excellent model for the study of the dynamics of sperm stored by females and for establishing a possible association between the copulatory behaviours of males and sperm viability for the sperm stored in the female reproductive tract.

Using $H$. pluchei as a study species, our aims in this study are as follows. First, we aim to evaluate whether there is any difference in sperm viability in females from that in males. This would provide us with information regarding how stressful the female 'environment' is from a selective perspective. Second, we aim to investigate the temporal variation in sperm viability inside the female genital tract, taking insemination as a reference point. This would assess whether sperm viability is a gradual process. Third, we aim to link the copulatory behaviours of males with the patterns of sperm viability found in females, as an approach to assess the role of such behaviours as courtship traits under selection via cryptic female choice. We predict that: (1) the sperm viability will be higher in the male spermatic bulbs compared with that in females; (2) the sperm viability will decrease over time during storage; and (3) an increase in male copulatory behaviours will have a positive effect on sperm viability while sperm are within females.

\section{MATERIAL AND METHODS}

\section{SPIDER COLLECTION AND REARING}

During the spring-summer period of 2017-2018 and 2018-2019, we collected subadult males and females of $H$. pluchei within the campus of the Universidad Nacional de Córdoba (UNC), Argentina. We placed the specimens in cylindrical plastic containers $(8 \mathrm{~cm}$ wide $\times 15 \mathrm{~cm}$ high) covered inside with paper (to provide them with a surface suitable for web construction) and with a cotton ball soaked in water as a source of humidity, under a $12 \mathrm{~h}-12 \mathrm{~h}$ light-dark photoperiod. Individuals were fed once a week with adult Drosophila melanogaster and larvae of Tenebrio molitor Linnaeus, 1758 until the spiders reached adulthood. For future reference, we deposited all used animals in the spider collection of the Laboratorio de Biología Reproductiva y Evolución, Instituto de Ecología y Diversidad Animal (IDEA-UNC), Córdoba, Argentina.

\section{GENERAL CONDITIONS FOR OBSERVATION}

We transferred females 2 days after reaching adulthood (measured as the time elapsed from their last moult) to individual mating arenas ( $8 \mathrm{~cm}$ wide $\times 12 \mathrm{~cm}$ high) $24 \mathrm{~h}$ before the trials. Previous studies have indicated that this period allows females to construct webs and acclimate (Calbacho-Rosa et al., 2013; Cargnelutti et al., 2018). Then, we introduced a male in the arena to copulate. If the male did not copulate, after $15 \mathrm{~min}$ it was removed and replaced by another male. If the second male was unable to mate, we removed it from the mating arena, and the female was tested again $24 \mathrm{~h}$ later. After completion of copulation, individuals were kept for $10 \mathrm{~min}$ in the mating arena to confirm that they had no intention of returning to mating. The female was kept alive as necessary according to our experimental design (see below, 'Experimental design'). We recorded the following copulatory behavioural aspects: the number of pedipalp movements, the number of body vibrations performed by the mating pair during copulation, and the duration of the postinsemination behaviour (in seconds). These behaviours were recorded using a stereomicroscope equipped with a Logitech QuickCam pro-9000 digital camera. Finally, the tibia-patella segments of the first pair of legs were measured in both males and females using IMAGEJ software (Schneider et al., 2012) to provide an estimate of the sizes of the individuals, as commonly done in pholcid spiders (Uhl et al., 2004; Calbacho-Rosa et al., 2010, 2012, 2019).

\section{EXPERIMENTAL DESIGN}

To establish whether there was an effect of the female on sperm viability, we created a two-level categorical variable that indicated how long the sperm pool was retained inside the female genital tract. The first level consisted of a group of females inseminated 4 days before (hereafter, 'females 4 days' group; $N=10$ ), representing a short-term temporal gap. The second level consisted of females inseminated 15 days before (hereafter, 'females 15 days' group; $N=20$ ), representing a long-term temporal effect. This long-term effect allowed us to document sperm viability that would closely resemble what occurs for this trait when the female is close to laying eggs. Also, the idea of having these two levels was to compare the sperm viability over time without the need for more couples, because it is logistically challenging to obtain virgin females for experiments. In these two experimental groups, we measured the sperm viability and the number of sperm stored in females in addition to the number of pedipalp 
movements, number of body vibrations performed by the mating pair during copulation, and duration of the post-insemination behaviour.

\section{PREPARATION OF SPERM STORED IN FEMALES}

Females of both time levels were anaesthetized by cold $\left(-28{ }^{\circ} \mathrm{C}\right)$, in order that we could dissect the uterus externus under a stereomicroscope (Nikon SMZ 1500). For this, we gently crushed the uterus externus in a microcentrifuge tube with $75 \mu \mathrm{L}$ of 'spider saline solution' $\left(3.26 \mathrm{~g} \mathrm{NaCl}, 0.13 \mathrm{~g} \mathrm{KCl}, 0.30 \mathrm{~g} \mathrm{CaCl}_{2} \cdot 2 \mathrm{H}_{2} \mathrm{O}\right.$, $0.26 \mathrm{~g} \mathrm{MgCl}_{2} .6 \mathrm{H}_{2} \mathrm{O}$ and $250 \mathrm{~mL}$ of distilled water; Albo $\&$ Peretti, 2015) using fine-tipped tweezers to release the sperm into the solution. We centrifuged the sperm solution for $6 \mathrm{~min}$ at $1678 \mathrm{~g}$. We confirmed that this speed was appropriate to precipitate the sperm by analysing a $10 \mu \mathrm{L}$ sample of the supernatant under a phase-contrast microscope (Nikon Eclipse 50i). This confirmed the absence of sperm in the supernatant in a preliminary pilot experiment. Finally, after discarding $40 \mu \mathrm{L}$ of supernatant, $35 \mu \mathrm{L}$ was homogenized by vortex for $10 \mathrm{~s}$. We can be sure that our method of extracting the sperm from the storage structures does not damage the cells, as documented by Cargnelutti et al. (2019). Nonetheless, it is essential to remember that spider sperm are covered by a protein sheath, which could give them extra protection.

QUANTIFICATION OF SPERM VIABILITY USING CALCEIN ACETOXYMETHYL ESTER AND ETHIDIUM HOMODIMER-1

We incubated $10 \mu \mathrm{L}$ of the $35 \mu \mathrm{L}$ sperm solution for $30 \mathrm{~min}$ in darkness at room temperature $\left(26^{\circ} \mathrm{C}\right)$, with $1 \mu \mathrm{L}$ of $20 \mu \mathrm{M}$ calcein acetoxymethyl ester (CAM) and $1 \mu \mathrm{L}$ of $40 \mu \mathrm{M}$ ethidium homodimer-1 (EthD1). All samples were analysed using an inverted epifluorescence microscope (Leica DiM8; RHODLP filter; excitation, $540 / 545 \mathrm{~nm}$; emission, $590 \mathrm{~nm}$ ). Calcein acetoxymethyl ester is a lipophilic vital dye that, after entering viable cells, is converted to calcein by intracellular esterases. This conversion leads to an intense green fluorescence, which is retained only by cells with an intact plasma membrane (Weston \& Parish, 1990; Bratosin et al., 2005). Furthermore, EthD-1 produces red fluorescence when it penetrates dead cells and is conjugated with the DNA inside the nucleus (Kato et al., 2002). We calculated the proportion of live sperm by counting a minimum of 200 cells when this was possible. The proportion of viable sperm was estimated using the following equation: sperm viability $=$ number of cells stained green/total number of cells counted (Cargnelutti et al., 2019).

\section{QUANTIFICATION OF THE AMOUNT OF SPERM STORED} IN FEMALES

We used $20 \mu \mathrm{L}$ of the remaining $35 \mu \mathrm{L}$ of the sperm solution to estimate the number of sperm stored by the females in both experimental groups. We placed $10 \mu \mathrm{L}$ of the sample in a Neubauer chamber for sperm counting using a phase-contrast microscope (Nikon Eclipse 50i). We estimated the total number of sperm in $35 \mu \mathrm{L}$ using the following equation: total number of sperm $=(35 \mu \mathrm{L} \times$ number of sperm counted $) / 0.4 \mu \mathrm{L}$ (Albo \& Peretti, 2015; Cargnelutti et al., 2018).

\section{PREPARATION OF SPERM STORED IN MALES AND QUANTIFICATION OF SPERM VIABILITY USING CAM/ ETHD-1}

We anaesthetized by cold $\left(-28{ }^{\circ} \mathrm{C}\right)$ virgin adult males (4-10 days after their last moult, $N=29$ ) and removed their sperm bulbs from the pedipalps (hereafter, 'bulbs'). In spiders, the bulbs are structures in the males' pedipalps that function as a sperm reservoir for copulation after the sperm induction process. We can define the process of sperm induction as the filling of the male pedipalps (male reproductive structures) with sperm secreted from the male gonopore before a male searches for females (Foelix, 2011). We gently crushed the bulbs in a microcentrifuge tube with $50 \mu \mathrm{L}$ of 'spider saline solution' using fine-tipped tweezers to release the sperm into the solution. We centrifuged the sperm solution at $1678 \mathrm{~g}$ for $5 \mathrm{~min}$. We resuspended the resulting pellet in $20 \mu \mathrm{L}$ of 'spider saline solution'. To measure sperm viability, we incubated $10 \mu \mathrm{L}$ of the sperm solution for $30 \mathrm{~min}$ in darkness at room temperature $\left(26{ }^{\circ} \mathrm{C}\right)$ with $1 \mu \mathrm{L}$ of $20 \mu \mathrm{M} \mathrm{CAM}$ and $1 \mu \mathrm{L}$ of $40 \mu \mathrm{M}$ EthD-1. The proportion of viable sperm was estimated using the following equation: sperm viability $=$ number of cells stained green/total number of cells counted (Cargnelutti et al., 2019).

\section{STATISTICAL ANALYSIS}

\section{Sperm viability in males and females}

We compared the proportion of viable spermatozoa inside the male bulbs and in the 'females 4 days' and 'females 15 days' groups using a generalized linear mixed model following a binomial distribution (logit link function) (Holman, 2009; Eckel et al., 2017). We included male identity as a random factor because we reused one male in the 'females 4 days' group and another male in the 'females 15 days' group. We added to the model the denominator used to calculate the proportion by the weights argument (Zuur et al., 2009; Dunn \& Smyth, 2018) from the glmer function (lme4 package for R; Bates et al., 2015). We also added 
a second random factor to control the overdispersion of the model, which includes one level per observation.

\section{Sperm viability and male copulatory behaviours}

We applied a generalized linear mixed model with a binomial distribution (logit link function) (Holman, 2009; Eckel et al., 2017) to investigate the effects of male copulatory behaviours on sperm viability. As in the previous model, we included the denominators of proportions in the model using the weights argument (as suggested by Zuur et al., 2009; Dunn \& Smyth, 2018) of the glmer function. Notice that there was no need for correction of overdispersion in this case. Before these analyses, we centred and scaled all explanatory variables using the scale function, available in the $\mathrm{R}$ base package ( $\mathrm{R}$ Core Team, 2019). We applied this procedure because the variables in the model had different orders of magnitude, making it difficult for the model to converge. We entered the number of pedipalp movements, the number of body vibrations performed by the mating pair during copulation, and the duration of the post-insemination behaviour. We also added two variables that might influence sperm viability and have some association with the copulatory courtship process: the intersexual difference in size and the number of sperm stored by the females. We defined the intersexual difference in size by subtracting the size of the female from the size of the male that formed the mating pair. This procedure resulted in a continuous variable with negative values (larger females than males) and positive values (larger males than females). The second variable, the number of sperm stored by the females, would control for any effect on sperm viability in the female associated with the number of sperm stored inside the uterus externus. For example, females with more sperm in the uterus externus might have higher sperm viability.

It is essential to mention that it was not possible to obtain one value of sperm stored by females in the ' 15 days females' group (one of 20 ) because of a problem with the sample during the sperm count. The sample was not adequate to make a reliable sperm count because the spermatozoa could not be distinguished. Bearing this in mind, we opted to impute this one value using the $k$-nearest neighbour function from the R Bnstruct package (Franzin et al., 2017). This method replaces the missing value in the data set with the median, taking into account the value of $k$ (where $k$ is the number of neighbours used to calculate the median). We used the cut-off line as a criterion for imputing data as suggested by Bennett (2001), where the amount of missing data is not $>10 \%$ of the total data, because in this way the results would not be biased (reviewed by Dong \& Peng, 2013). We started with a model that contained only the additive effects of variables, excluding the interactions to avoid overparametrization of the model. We simplified the model by selecting variables using the likelihood-ratio test method using the anova function (Zuur et al., 2009).

\section{RESULTS}

\section{SPERM VIABILITY IN MALES AND FEMALES}

We found significant differences in sperm viability among males and both female treatments $\left(\chi^{2}=54.472\right.$, d.f. $=2, P<0.001)$. A post hoc test indicated that sperm viability in males was significantly higher than in both female groups. Sperm viability for both female groups did not differ (Table 1; Fig. 1). Thus, sperm viability was as follows: males, $99.6 \%$; 'females 4 days', $90.4 \%$; and 'females 15 days', $89.4 \%$.

\section{SPERM VIABILITY IN FEMALE AND MALE COPULATORY BEHAVIOURS}

The best model that described the variation in sperm viability in the 'females 15 days' group contained the duration of the post-insemination behaviour and the intersexual difference in size (Supporting Information, Table S1). On the one hand, females that mated with males larger than themselves stored fewer viable sperm $\left(\chi^{2}=11.064\right.$, d.f. $=1, P=0.001$; Fig. 2 A), whereas females that mated with males that performed a more extended duration of post-insemination behaviour stored a higher proportion of viable sperm $\left(\chi^{2}=4.280\right.$, d.f. $=1, P=0.038$; Fig. 2B). On the other hand, for the 'females 4 days' group none of the explanatory variables (the same ones used for the previous model except for pedipalp movements, owing to a lack of convergence of the model) explained variation in

Table 1. Contrast table between treatments (males vs. 'females 4 days' vs. 'females 15 days')

\begin{tabular}{lllll}
\hline Contrast & $\begin{array}{l}\text { Odds } \\
\text { ratio }\end{array}$ & SE & $z$-ratio & $P$-value \\
\hline $\begin{array}{l}\text { Males vs. } \\
\text { 'females 4 days' }\end{array}$ & 24.217 & 11.633 & 6.635 & $<0.0001$ \\
$\begin{array}{c}\text { Males vs. 'females } \\
\text { 15 days' }\end{array}$ & 23.912 & 10.396 & 7.302 & $<0.0001$ \\
$\begin{array}{c}\text { 'Females 4 days' vs. } \\
\text { 'females 15 days' }\end{array}$ & 0.987 & 0.315 & 0.040 & 0.9991 \\
\hline
\end{tabular}

A significant difference can be seen between the male treatment and both female treatments. The odds ratio value indicates the probability of the effect appearing (i.e. the presence of viable spermatozoa); therefore, we can see that the probability of the effect appearing in the male treatment is 24 times greater than in the 'females 4 days' treatment and 23 times greater than in the 'females 15 days' treatment, whereas it is the same between the 'females 4 days' and 'females 15 days' treatments. 
sperm viability (Supporting Information, Table S2). Additionally, we opted to perform two tests involving male size. First, we tested for a correlation between male size and the duration of the post-insemination behaviour in the 'female 15 days' group, which proved to be absent $\left(r^{2}=-0.270, P=0.294\right)$. Second, we verified the relationship between male size and sperm viability in males, and we found that larger males had a higher sperm viability value $\left(\chi^{2}=5.228\right.$, d.f. $\left.=1, P=0.022\right)$, although the magnitude of the variation was subtle.

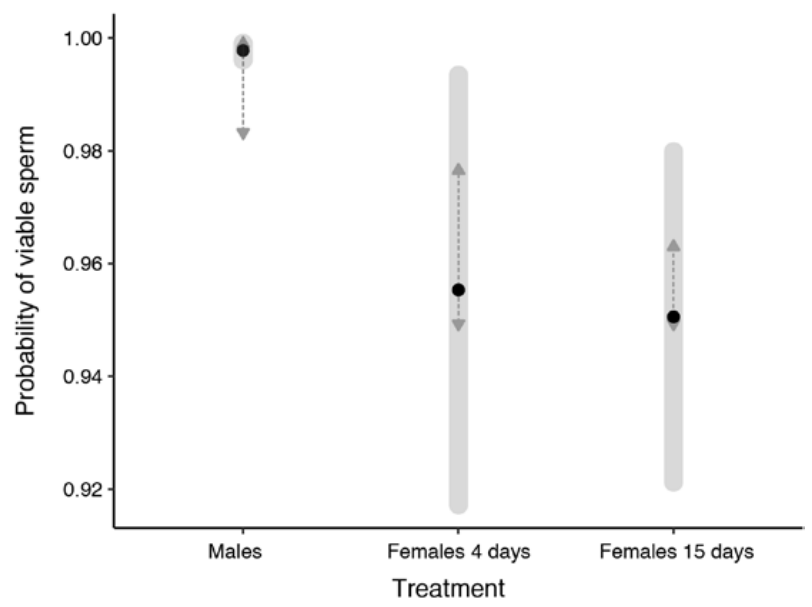

Figure 1. Probability of viable spermatozoa in males and in 'females 4 days' and 'females 15 days' groups after copulation. Grey bars represent the average confidence intervals for each treatment. Grey arrows indicate comparisons between the means. If two or more arrows overlap, there is no significant difference according to $\alpha=0.05$.

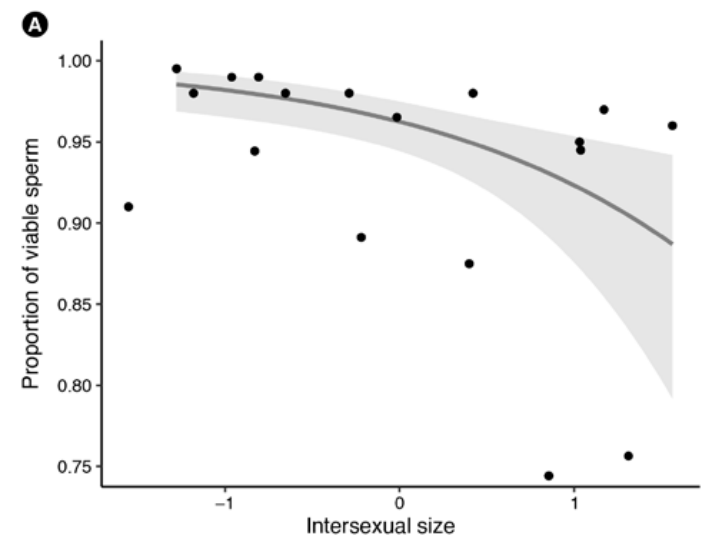

\section{DISCUSSION}

We found support for the first prediction, i.e. lower sperm viability within females than in males. A possible explanation for this is that the female reproductive tract is a highly selective environment (Birkhead et al., 1993; Pitnick et al., 2009; Fitzpatrick \& Lüpold, 2014). It is known that females impose mechanical, physiological and/or biochemical barriers (e.g. glandular secretions), altering sperm performance and thereby allowing only a small fraction of the ejaculate to reach the eggs (reviewed by Fitzpatrick \& Lüpold, 2014; Pitnick et al., 2020). This selective environment might have evolved initially via natural selection, to avoid fertilization by sperm with morphological abnormalities or low motility or sperm not suitable for fertilization (Pitnick et al., 2009). The female tract might have evolved further to favour males that perform better in a sperm competition scenario or sperm that covary positively with the genetic condition of males (Keller \& Reeve, 1995). Related to this, for example, the competitiveness of sperm in the yellow dung fly (Scatophaga stercoria) was associated with the survival of offspring (Hosken et al., 2003; reviewed by Pitnick et al., 2009). Regardless of whether an ejaculate competes with the ejaculate of another male, its success depends primarily on its ability to deal with the female genital tract (Fitzpatrick \& Lüpold, 2014; e.g. Miller \& Pitnick, 2002). Following the logic of a selective environment, Hosken et al. (2001) proposed that glandular secretions in the yellow dung fly could cause sperm mortality [however, Bernasconi et al. (2002) demonstrated that such secretions do not have anti-sperm properties]. Interestingly, $H$. pluchei females have a gland in their uterus externus, which

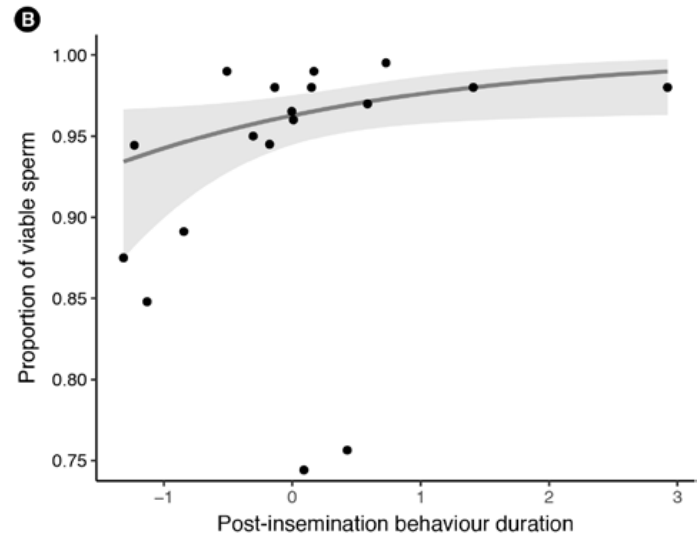

Figure 2. A, proportion of viable spermatozoa in the uterus externus of 'females 15 days' after copulation as a function of intersexual size. We defined the intersexual size by subtracting the size of the female from the size of the male that formed the mating pair. B, proportion of viable spermatozoa in the uterus externus of 'females 15 days' after copulation as a function of the duration of the post-insemination behaviour. Grey bands around the estimated curves represent the confidence interval of the curve. 
is in constant contact with stored sperm (Huber, 1995), but the glandular function is unknown. In another species of the family, Pholcus phalangioides (Fuesslin, 1775), Uhl (1996) suggested that the secretions of the uterine glands could work to establish an adequate ionic balance inside the uterus externus of the females, to avoid the desiccation of the sperm, to fight bacterial or fungal infections or, more probably, as a matrix to avoid the loss of the spermatozoa by the female genital opening. Given the reduction in sperm viability, one hypothesis is that the secretions of the uterine gland in H. pluchei have 'anti-spermatic' properties selecting the most suitable spermatozoa within an ejaculate or, as demonstrated in social insects, it would keep sperm alive (den Boer et al., 2008, 2009). Moreover, given that females of $H$. pluchei are polyandric (Dutto et al., 2011), a selective environment in their uterus externus might filter spermatozoa of the fittest male. However, we cannot exclude the possibility that both options operate at the same time: females imposing a selection criterion and, at the same time, maintaining the viability of the spermatozoa once these cells pass this criterion. Another possible explanation for the decrease in sperm viability in females is their age. Ageing might compromise the ability of females to maintain viable sperm by leading to a process of reproductive senescence (Radhakrishnan \& Fedorka, 2011). Although we have not optimized our experimental protocol to test for effects of female age on sperm viability, the fact that the 'females 4 days' vs. 'females 15 days' groups did not differ in sperm viability suggests that sperm ageing is not a problem.

Although all cells go through a process of cellular senescence, sperm are especially susceptible to ageing (White et al., 2008). From the moment of sperm production, cells accumulate damage, mainly attributable to reactive oxygen species (Radhakrishnan $\&$ Fedorka, 2011) and, once inside the females, this damage continues to accumulate over time. However, we found that sperm viability remained stable within our storage time window, suggesting the action of a protective mechanism. Once inside the storage sites of the female, sperm can be compacted in a way that could provide some protection against endogenous respiration and osmotic stress (Mann, 1967; Reinhardt, 2007). In our study model, sperm are compacted inside the uterus externus, possibly mediated by glandular secretions, as suggested for P. phalangioides (Uhl, 1994, 1996). Such a strategy is likely to help prevent a reduction in sperm viability over time. However, the absence of studies on spider sperm physiology in both male bulbs and female sperm spermathecae implies possible exceptions to the general patterns mentioned above. Therefore, we are aware of the need for speciesspecific studies to corroborate these hypotheses.
The decrease of viable spermatozoa in the uterus externus of females might well be a consequence of a male-male competition process. Engqvist (2012) proposed a theoretical model whereby the viability of sperm decreases with the mating rate of females. This author concluded that males subjected to greater sperm competition (those belonging to polyandrous species, such as our study model; see Dutto et al., 2011) would produce more viable sperm, but with a higher mortality rate within the female reproductive tract. This sperm competition scenario is compatible with the positive relationship between sperm swimming ability and extra-pair paternity in birds (Kleven et al., 2009). Although Engqvist's argument assumes a mechanism of sperm competition by fair raffles (see Parker, 1990), this line of reasoning applies to other mechanisms of sperm competition, such as sperm precedence. The selective pressure will be stronger in animals with sperm precedence favourable to the last mating male (Engqvist, 2012), which is the case for H. pluchei (Kaster \& Jakob, 1997).

Another result that might be linked to a cryptic female choice scenario was the relationship between an extended post-insemination behaviour and an increase in sperm viability in the 'females 15 days' group. This might indicate the importance of the time from copulation to the appearance of the postcopulatory effect (which develops during copulation, e.g. postinsemination behaviour duration). However, to be entirely sure of this reasoning, we would need to increase the sample size of the 'females 4 days' group. Sperm viability is related to the reproductive success of males in several taxa (Hunter \& Birkhead, 2002; García-González \& Simmons, 2005; Simmons \& Fitzpatrick, 2012; Tourmente et al., 2019). In mammals, for example, sperm competition has selected for elongated tails (Thompson et al., 2018), but sperm are sensitive to hyperosmotic stress (Santymire et al., 2006). In the case of $H$. pluchei, we are unaware of the factors that select in favour and against sperm viability. In this species, sperm viability proved to be higher in females experiencing a more extended postinsemination behaviour, which would be selecting for males able to perform this behaviour for a longer time. However, among the possible functions of postinsemination behaviour, it has been proposed to act as postcopulatory mate guarding or to stimulate the female through imperceptible movements or pressure within the female genitalia (i.e. copulatory courtship) even though the male is apparently immobile (Cargnelutti et al., 2018). The phenomenon of immobility during copulation has been studied in other animals. For example, the immobility of females of the flour beetle Tribolium castaneum (Herbst, 1797) increases sperm transfer and paternity and, being 
under female control, this is interpreted as a crucial moment for cryptic female choice (Bloch Qazi, 2003).

An alternative explanation could be that healthier males are those that can remain attached to females for longer, considering that the female is the sex that ends copulation (F. Cargnelutti, pers. obs.). At the same time, these males are those that present higher sperm viability (for a theoretical framework, see Fitzpatrick \& Lüpold, 2014). However, we did not find a correlation between larger males, a parameter related to their condition and other life-history traits (Andersson, 1994; Johnstone, 1995; Uhl et al., 2004), and the time they remain attached to the females.

Interestingly, we have not found a relationship between the number of pedipalp movements, performed during phase I of copulation, and sperm viability in females. We are unaware of studies examining copulatory courtship and sperm viability in vertebrates. The closest to this are studies describing a positive relationship between copulatory courtship and sperm motility in birds (e.g. Chargé et al., 2010). Conversely, several studies in pholcid spiders have suggested that genital movements could stimulate the female, considering them also as a type of copulatory courtship (Huber \& Eberhard, 1997; Schäfer \& Uhl, 2002; Peretti \& Eberhard, 2010; Calbacho-Rosa \& Peretti, 2015). Although there is no evidence for a mechanism of cryptic female choice triggered by male pedipalp movements, females might still assess their mating partner through this behaviour. However, we are aware that the female might use more than one criterion to favour specific male phenotypes. We have demonstrated here that sperm viability values in females are independent of this behaviour. Future research should clarify whether there is any function of phase I apart from sperm transfer (Cargnelutti et al., 2018).

It is paradoxical that females that mated with larger males stored relatively fewer viable sperm, even though larger males had higher sperm viability in their bulbs (for an example where a positive correlation existed between sperm viability and sperm number, see Rodriguez de Souza et al., 2020). One explanation can be framed in the context of mate choice. In many animals, females prefer to mate with larger males because their size is a positive indicator of condition (Andersson, 1994; Johnstone, 1995). In species with a sperm priority favourable to the last male, virgin females tend to be less selective than copulated females (Schäfer \& Uhl, 2004). This lower selectivity might favour copulations with smaller males, who might have limited possibilities of copulating with inseminated females. Bearing in mind that during mating $H$. pluchei males can remove the sperm stored from previous copulations (Calbacho-Rosa et al., 2013), small males could transfer a higher proportion of viable spermatozoa to ensure higher paternity when compared with large males.

Finally, the link between sperm viability and male copulatory behaviour we document here has implications for understanding within- and between-species variation in this regard. The idea that females can use copulatory behaviour to bias paternity has been suggested (Eberhard, 1996; Bloch Qazi, 2003; Eberhard \& Lehmann, 2019). In this regard, whether female choice drives sperm viability based on male postcopulatory behaviour in $H$. pluchei needs further testing. Also, it would be worthwhile exploring the same idea using other animal systems.

\section{ACKNOWLEDGEMENTS}

We thank German Gonzalez for his useful help in the statistical analysis and Cleia Gasparini, Maximiliano Tourmente, Jackelyn Kembro and Nelson Ferreti for their useful comments on a previous version of this paper. We also thank two anonymous reviewers for their helpful comments. Financial support was provided by the Consejo Nacional de Investigaciones Científicas y Técnicas (CONICET), Fondo para la Investigación Científica y Tecnológica (FONCYT) and Secretaría de Ciencia y Tecnología de la Universidad Nacional de Córdoba (SECYT). L.E.C.-S. received a post-doctoral grant from Capes/Brazil (PNPD 20132737). This study was conducted in compliance with the 'Guidelines for the use of animals in research and teaching', published in Animal Behaviour (2020, 159: I-XI), and with the laws of the country where the research was conducted. The authors declare that they have no conflicts of interest.

\section{REFERENCES}

Alberti G. 1990. Comparative spermatology of Araneae. Acta Zoologica Fennica 190: 17-34.

Albo MJ, Peretti AV. 2015. Worthless and nutritive nuptial gifts: mating duration, sperm stored and potential female decisions in spiders. PLoS One 10: e0129453.

Andersson MB. 1994. Sexual selection. Princeton: Princeton University Press.

Archibald KE, Minter LJ, Lewbart GA, Bailey CS. 2014. Collection and characterisation of semen from Chilean rose tarantulas (Grammostola rosea). American Journal of Veterinary Research 75: 929-936.

Baer B, Armitage SA, Boomsma JJ. 2006. Sperm storage induces an immunity cost in ants. Nature 441: 872-875.

Baer B, Eubel H, Taylor NL, O'Toole N, Millar AH. 2009. Insights into female sperm storage from the spermathecal fluid proteome of the honeybee Apis mellifera. Genome Biology 10: R67. 
Bates D, Maechler M, Bolker B, Walker S, Christensen RHB, Singmann H, Bolker MB. 2015. Package 'Ime4'. Convergence 12: 2.

Bennett DA. 2001. How can I deal with missing data in my study? Australian and New Zealand Journal of Public Health 25: 464-469.

Bernasconi G, Hellriegel B, Heyland A, Ward PI. 2002. Sperm survival in the female reproductive tract in the fly Scathophaga stercoraria (L.). Journal of Insect Physiology 48: 197-203.

Birkhead TR, Møller AP, Sutherland WJ. 1993. Why do females make it so difficult for males to fertilise their eggs? Journal of Theoretical Biology 161: 51-60.

Bloch Qazi MC. 2003. A potential mechanism for cryptic female choice in a flour beetle. Journal of Evolutionary Biology 16: 170-176.

den Boer SP, Boomsma JJ, Baer B. 2008. Seminal fluid enhances sperm viability in the leafcutter ant Atta colombica. Behavioral Ecology and Sociobiology 62: 1843-1849.

den Boer SP, Boomsma JJ, Baer B. 2009. Honey bee males and queens use glandular secretions to enhance sperm viability before and after storage. Journal of Insect Physiology 55: 538-543.

Bratosin D, Mitrofan L, Palii C, Estaquier J, Montreuil J. 2005. Novel fluorescence assay using calcein-AM for the determination of human erythrocyte viability and aging. Cytometry. Part A: the Journal of the International Society for Analytical Cytology 66: 78-84.

Calbacho-Rosa L, Cargnelutti F, Peretti AV, CostaSchmidt LE. 2019. Female secondary sexual traits in spiders: adaptive interpretations of the sternum projection in the pholcid Holocnemus pluchei. Zoology 136: 125694.

Calbacho-Rosa L, Córdoba-Aguilar A, Peretti AV. 2010. Occurrence and duration of postcopulatory mate guarding in a spider with last sperm precedence. Behavior 147: 1267-1283.

Calbacho-Rosa L, Galicia-Mendoza I, Dutto MS, Córdoba-Aguilar A, Peretti AV. 2013. Copulatory behavior in a pholcid spider: males use specialised genitalic movements for sperm removal and copulatory courtship. Naturwissenschaften 100: 407-416.

Calbacho-Rosa L, Moreno-García MA, Lanz-Mendoza H, Peretti AV, Córdoba-Aguilar A. 2012. Reproductive activities impair immunocompetence in Physocyclus dugesi (Araneae: Pholcidae). The Journal of Arachnology 40: 18-22.

Calbacho-Rosa L, Peretti AV. 2015. Copulatory and postcopulatory sexual selection in haplogyne spiders, with emphasis on Pholcidae and Oonopidae. In: Peretti AV, Aisenberg A, eds. Cryptic female choice in arthropods: patterns, mechanisms and prospects. Cham: Springer, 109-144.

Cargnelutti F. 2020. Selección sexual en arañas: patrones $y$ mecanismos en un modelo de haplogína. Unpublished D. Phil. Thesis, Universidad Nacional de Córdoba.

Cargnelutti F, Calbacho-Rosa L, Córdoba-Aguilar A, Peretti AV. 2018. Patterns of sperm transfer behavior in a pholcid spider with two distinct copulatory phases. Journal of Insect Behavior 31: 616-628.

Cargnelutti F, Uñates D, Vrech DE, Bollatti F, CalbachoRosa L, Córdoba-Aguilar A, Peretti, AV. 2019. Sperm viability in spiders: a first approach using Holocnemus pluchei (Scopoli, 1763) (Synspermiata: Pholcidae). The Journal of Arachnology 47: 52-56.

Chargé R, Saint Jalme M, Lacroix F, Cadet A, Sorci G. 2010. Male health status, signalled by courtship display, reveals ejaculate quality and hatching success in a lekking species. Journal of Animal Ecology 79: 843-850.

Dávila F, Chérasse S, Boomsma JJ, Aron S. 2015. Ant sperm storage organs do not have phenoloxidase constitutive immune activity. Journal of Insect Physiology 78: 9-14.

Demary KC. 2005. Sperm storage and viability in Photinus fireflies. Journal of Insect Physiology 51: 837-841.

Dong Y, Peng C-YJ. 2013. Principled missing data methods for researchers. SpringerPlus 2: 222.

Dunn PK, Smyth GK. 2018. Generalised linear models with examples in $R$. New York: Springer.

Dutto MS, Calbacho-Rosa L, Peretti AV. 2011. Signalling and sexual conflict: female spiders use stridulation to inform males of sexual receptivity. Ethology 117: 1040-1049.

Eberhard W. 1996. Female control: sexual selection by cryptic female choice. Princeton: Princeton University Press.

Eberhard WG. 2004. Why study spider sex: special traits of spiders facilitate studies of sperm competition and cryptic female choice. The Journal of Arachnology 32: 545-557.

Eberhard WG. 2015. Cryptic female choice and other types of postcopulatory sexual selection. In: Peretti AV, Aisenberg A, eds. Cryptic female choice in arthropods: patterns, mechanisms and prospects. Cham: Springer, 1-26.

Eberhard WG, Lehmann GU. 2019. Demonstrating sexual selection by cryptic female choice on male genitalia: what is enough? Evolution 73: 2415-2435.

Eckel BA, Guo R, Reinhardt K. 2017. More pitfalls with sperm viability staining and a viability-based stress test to characterise sperm quality. Frontiers in Ecology and Evolution 5: 165.

Engqvist L. 2012. Evolutionary modeling predicts a decrease in postcopulatory sperm viability as a response to increasing levels of sperm competition. The American Naturalist 179: 667-677.

Fitzpatrick JL, Lüpold S. 2014. Sexual selection and the evolution of sperm quality. Molecular Human Reproduction 20: $1180-1189$.

Foelix RF. 2011. Biology of spiders, 3rd edn. New York: Oxford University Press.

Franzin A, Sambo F, Di Camillo B. 2017. bnstruct: an R package for Bayesian Network structure learning in the presence of missing data. Bioinformatics 33: 1250-1252.

García-González F, Simmons LW. 2005. Sperm viability matters in insect sperm competition. Current Biology 15: 271-275.

Gasparini C, Evans JP. 2013. Ovarian fluid mediates the temporal decline in sperm viability in a fish with sperm storage. PLoS One 8: e64431.

Greeff M, Schmid-Hempel P. 2008. Sperm viability in the male accessory testes and female spermathecae of the bumblebee Bombus terrestris (Hymenoptera: Apidae). European Journal of Entomology 105: 849-854. 
Heifetz Y, Rivlin PK. 2010. Beyond the mouse model: using Drosophila as a model for sperm interaction with the female reproductive tract. Theriogenology 73: 723-739.

Herberstein ME, Schneider JM, Uhl G, Michalik P. 2011. Sperm dynamics in spiders. Behavioral Ecology 22: 692-695.

Holman L. 2009. Sperm viability staining in ecology and evolution: potential pitfalls. Behavioral Ecology and Sociobiology 63: 1679-1688.

Holman L, Snook RR. 2008. A sterile sperm caste protects brother fertile sperm from female-mediated death in Drosophila pseudoobscura. Current Biology 18: 292-296.

Hosken DJ, Garner TWJ, Ward PI. 2001. Sexual conflict selects for male and female reproductive characters. Current Biology 11: 489-493.

Hosken DJ, Martin OY, Born J, Huber F. 2003. Sexual conflict in Sepsis cynipsea: female reluctance, fertility and mate choice. Journal of Evolutionary Biology 16: 485-490.

Huber BA. 1995. Copulatory mechanism in Holocnemus pluchei and Pholcus opilionoides, with notes on male cheliceral apophyses and stridulatory organs in Pholcidae (Araneae). Acta Zoologica 76: 291-300.

Huber BA. 2014. Pholcidae. In: Roig-Juñent S, Claps LE, Morrone JJ, eds. Biodiversidad de Artrópodos Argentinos, Vol. 3. 3rd ed. Sociedad Entomológica Argentina, 131-140.

Huber BA, Eberhard WG. 1997. Courtship, copulation, and genital mechanics in Physocyclus globosus (Araneae, Pholcidae). Canadian Journal of Zoology 75: 905-918.

Hunter FM, Birkhead TR. 2002. Sperm viability and sperm competition in insects. Current Biology 12: 121-123.

Johnstone RA. 1995. Sexual selection, honest advertisement and the handicap principle: reviewing the evidence. Biological Reviews 70: 1-65.

Kaster JL, Jakob EM. 1997. Last-male sperm priority in a haplogyne spider (Araneae: Pholcidae): correlations between female morphology and patterns of sperm usage. Annals of the Entomological Society of America 90: 254-259.

Kato M, Makino S, Kimura H, Ota T, Furuhashi T, Nagamura Y. 2002. Evaluation of mitochondrial function and membrane integrity by dual fluorescent staining for assessment of sperm status in rats. The Journal of Toxicological Sciences 27: 11-18.

Kekäläinen J, Evans JP. 2018. Gamete-mediated mate choice: towards a more inclusive view of sexual selection. Proceedings of the Royal Society B: Biological Sciencdes 285: 20180836.

Keller L, Reeve HK. 1995. Why do females mate with multiple males? The sexually selected sperm hypothesis. Advances in the Study of Behaviour 24: 291-316.

Kleven O, Fossøy F, Laskemoen T, Robertson RJ, Rudolfsen G, Lifjeld JT. 2009. Comparative evidence for the evolution of sperm swimming speed by sperm competition and female sperm storage duration in passerine birds. Evolution 63: 2466-2473.

Mann T. 1967. Sperm metabolism. In: Metz CB, Monroy A, eds. Fertilisation: comparative morphology, biochemistry, and immunology. New York: Academic Press, 99-116.
Michalik P, Lipke E. 2013. Male reproductive system of spiders. In: Nentwid W, ed. Spider ecophysiology. Berlin: Springer, 173-187.

Miller GT, Pitnick S. 2002. Sperm-female coevolution in Drosophila. Science 298: 1230-1233.

Orr, TJ, Zuk M. 2012. Sperm storage. Current Biology 22: R8-R10.

Parker GA. 1990. Sperm competition games: raffles and roles. Proceedings of the Royal Society B: Biological Sciences 242: 120-126.

Peretti AV, Eberhard WG. 2010. Cryptic female choice via sperm dumping favours male copulatory courtship in a spider. Journal of Evolutionary Biology 23: 271-281.

Pitnick S, Wolfner MF, Dorus S. 2020. Post-ejaculatory modifications to sperm (PEMS). Biological Reviews 95: 365-392.

Pitnick S, Wolfner MF, Suarez SS. 2009. Ejaculate-female and sperm-female interactions. In: Birkhead TR, Hosken DJ, Pitnick S, eds. Sperm biology. San Diego: Academic Press, 247-304.

$\mathbf{R}$ Core Team. 2019. $R$ : a language and environment for statistical computing. Vienna: R Foundation for Statistical Computing. Available at: https://www.R-project.org/

Radhakrishnan P, Fedorka KM. 2011. Influence of female age, sperm senescence and multiple mating on sperm viability in female Drosophila melanogaster. Journal of Insect Physiology 57: 778-783.

Reinhardt K. 2007. Evolutionary consequences of sperm cell aging. The Quarterly Review of Biology 82: 375-393.

Reinhardt K, Ribou AC. 2013. Females become infertile as the stored sperm's oxygen radicals increase. Scientific Reports 3: 2888.

Ribou AC, Reinhardt K. 2012. Reduced metabolic rate and oxygen radicals production in stored insect sperm. Proceedings of the Royal Society B: Biological Sciences 279: 2196-2203.

Rodriguez de Souza AR, Santos EF, Nascimento FSD, Stanyon R, Lino-Neto J, Beani L. 2020. Sexually dimorphic traits and male fertility in a paper wasp. Biological Journal of the Linnean Society 130: 555-562.

Rolff J, Siva-Jothy MT. 2003. Invertebrate ecological immunology. Science 301: 472-475.

Santymire RM, Marinari PE, Kreeger JS, Wildt DE, Howard J. 2006. Sperm viability in the black-footed ferret (Mustela nigripes) is influenced by seminal and medium osmolality. Cryobiology 53: 37-50.

Schäfer MA, Uhl G. 2002. Determinants of paternity success in the spider Pholcus phalangioides (Pholcidae: Araneae): the role of male and female mating behaviour. Behavioral Ecology and Sociobiology 51: 368-377.

Schäfer MA, Uhl G. 2004. Sequential mate encounters: female but not male body size influences female remating behavior. Behavioral Ecology 16: 461-466.

Schneider CA, Rasband WS, Eliceiri KW. 2012. NIH Image to ImageJ: 25 years of image analysis. Nature Methods 9: 671-675. 
Simmons LW. 2001. Sperm competition and its evolutionary consequences in the insects. Princeton: Princeton University Press.

Simmons LW, Fitzpatrick JL. 2012. Sperm wars and the evolution of male fertility. Reproduction 144: 519-534.

Snook RR, Hosken DJ. 2004. Sperm death and dumping in Drosophila. Nature 428: 939-941.

Stewart AD, Hannes AM, Rice WR. 2007. An assessment of sperm survival in Drosophila melanogaster. Evolution 61: 636-639.

Thompson SK, Kutchy NA, Kwok S, Rosyada ZN, Imumorin IG, Purwantara B, Memili E. 2018. Sperm: comparative morphology and function related to altered reproductive strategies and fertility in mammals. The Professional Animal Scientist 34: 558-565.

Tourmente M, Archer CR, Hosken DJ. 2019. Complex interactions between sperm viability and female fertility. Scientific Reports 9: 15366.

Tsuchiya K, Hayashi F. 2010. Factors affecting sperm quality before and after mating of calopterygid damselflies. PLoS One 5: e9904.

Uhl G. 1994. Genital morphology and sperm storage in Pholcus phalangioides (Fuesslin, 1775) (Pholcidae; Araneae). Acta Zoologica 75: 1-12.
Uhl G. 1996. Sperm storage secretion of female cellar spiders (Pholcus phalangioides; Araneae): a gel-electrophoretic analysis. Journal of Zoology 240: 153-161.

Uhl G, Schmitt S, Schäfer MA, Blanckenhorn W. 2004. Food and sex-specific growth strategies in a spider. Evolutionary Ecology Research 6: 523-540.

Vöcking O, Uhl G, Michalik P. 2013. Sperm dynamics in spiders (Araneae): ultrastructural analysis of the sperm activation process in the garden spider Argiope bruennichi (Scopoli, 1772). PLoS One 8: e72660.

Wigby S, Suarez SS, Lazzaro BP, Pizzari T, Wolfner MF. 2019. Sperm success and immunity. Current Topics in Developmental Biology 135: 287-313.

Weston SA, Parish CR. 1990. New fluorescent dyes for lymphocyte migration studies: analysis by flow cytometry and fluorescence microscopy. Journal of Immunological Methods 133: 87-97.

White J, Wagner RH, Helfenstein F, Hatch SA, Mulard H, Naves LC, Danchin E. 2008. Multiple deleterious effects of experimentally aged sperm in a monogamous bird. Proceedings of the National Academy of Sciences of the United States of America 105: 13947-13952.

Zuur A, Ieno EN, Walker N, Saveliev AA, Smith GM. 2009. Mixed effects models and extensions in ecology with $R$. New York: Springer Science and Business Media.

\section{SUPPORTING INFORMATION}

Additional Supporting Information may be found in the online version of this article at the publisher's web-site:

Table S1. Pairwise comparison between nested models ranked by Akaike information criterion value for the 'females 15 days' group. A value of $P>0.05$ indicates that the simplest model (the one from which a predictive variable was removed) explains the variation of the response variable in the same way as the model that includes that variable. Abbreviations: IS, intersexual size; PIBD, duration of post-insemination behaviour; PM, number of pedipalp movements; S, number of spermatozoa stored by the female; SV, proportion of viable spermatozoa; V, vibrations. The final model is in bold italics.

Table S2. Pairwise comparison between nested models ranked by Akaike information criterion value for the 'females 4 days' group. A value of $P>0.05$ indicates that the simplest model (the one from which a predictive variable was removed) explains the variation of the response variable in the same way as the model that includes that variable. Abbreviations: IS, intersexual size; PIBD, duration of post-insemination behaviour; S, number of spermatozoa stored by the female; $\mathrm{SV}$, proportion of viable spermatozoa; $\mathrm{V}$, vibrations; 1 , intercept. The final model is in bold italics. 